\title{
Comparative Effect of Different Potting Media on Vegetative and Reproductive Growth of Floral Shower (Antirrhinum majus L.)
}

\author{
Tahir Mehmood ${ }^{1, *}$, Waqas Ahmad ${ }^{1}, K_{\text {Khawaja Shafique Ahmad }}^{2}$, Jamil Shafi ${ }^{3}$, Muhammad Asif Shehzad ${ }^{4}$, \\ Muhammad Aqeel Sarwar ${ }^{4}$ \\ ${ }^{1}$ Institute of Horticultural Sciences, University of Agriculture, Faisalabad (38040) Pakistan \\ ${ }^{2}$ Department of Botany, University of Agriculture Faisalabad (38040) Pakistan \\ ${ }^{3}$ Department of Plant Pathology, University of Agriculture, Faisalabad (38040) Pakistan \\ ${ }^{4}$ Department of Agronomy, University of Agriculture, Faisalabad (38040) Pakistan \\ *Corresponding author: floricultureuaf@gmail.com
}

Copyright $@ 2013$ Horizon Research Publishing All rights reserved.

\begin{abstract}
This research project was conducted to investigate the comparative effect of different potting media with different compositions on growth and flowering of Antirrhinum majus L. 'Floral Shower'. The data for both morphological and physiological parameters analyzed statistically showed significant effect of media combinations over control values. Each treatment was consisted of 10 plants and was replicated thrice. Agricultural and municipal wastes are good, cheap potting media components for the production of flowering plants. An economical and high-quality production of 'Floral shower' can be attained by using most suitable media. The results regarding growth and flowering parameters showed significant increase in Leaf Mould potting media. The media containing Farm Yard Manure alone and in combination with silt with its higher $\mathrm{pH}$, showed least results for these parameters. On the other hand, plants grown in Farm Yard Manure comprising media provide minimum results for all the characteristics except for media nitrogen content which were statistically similar to control. Peat moss containing growing substrate also showed positive results for plants vegetative and reproductive growth. However, Farm Yard Manure was seen to prove less effective for better plant growth due to its less contribution for the availability of nutrients. Availability of Phosphorus contents in soil has positive relationship with growth and flowering indices. Maximum Phosphorus content was found when Farm Yard Manure and Leaf Mould were used alone in combination with silt + topsoil. Thus, it is suggested that Leaf Mould can be recommended as a standard potting media for Antirrhinum majus L. growth.
\end{abstract}

Keywords Potting Media, Growth \& Floral Attributes, Chemical Analysis, Antirrhinum Majus L.

\section{Introduction}

Antirrhinum majus L. belongs to family Scrophulariaceae is native of Mediterranean region. The consequences of DNA analyses have, led to drastic deviations in the circumscription of the family and the reclassified as a member of the Plantaginaceae [1]. Currently, 36 species and 20, 000 cultivars of Antirrhinum have been renowned [2]. It is commonly known as "Snapdragon" as its hinged flowers open and close like the mouth of a dragon when pinched at the sides with thumb. Snapdragon cultivars are classified on the basis of their growth and flowering response to day length and temperature [3].

Potting media plays a key role in quality and production of flowering plants. Natural soil and peat are the most used growing substrates for the container production of annual and perennial ornamental plants [4]. Potting media containing peat is commercially an expensive and non-reusable component but developing inexpensive alternatives by the use of nutrient-rich organic media can potentially results in reduction of fertilization and irrigation rates as well as also decrease nursery costs [5]. Peat is the most widely used substrate for potted plant production in nurseries and it accounts for a significant portion of the material used to grow potted plants [6].

Growing flower crops compared with traditional crops provide more marketing at both small and large scale for growers and it becoming more selective choice now days. Globally, horticultural crops are cultivated in more than 140 countries [7]. Potting soil mixes are the most important factors for the quality production of flowers in floriculture. Ornamental floral species tend to have a higher global demand, depending on people's preferences [8]. Correct combination of substrates for growing media to optimize plant growth is demanding and represents the cost 
production about $4-6 \%$ for bedding plants [9]. Potting media have positive effects against diseaases, Bulluck [10] observed that disease incidence of southern blight of tomato was $67 \%$ in tilled bare soil receiving synthetic fertilizers; whereas disease incidence was 3,12, and $16 \%$ in surface-mulched plots amended with a composted cotton-gin trash, swine manure, or a rye-vetch green manure.

Organic materials from agriculture, forestry, green areas, and livestock farming as well as residues from municipal and industrial waste are rich sources of different nutrients [11] and all have been strongly recommended for use as renewable resources in pot production, an effort that would help to palliate their harmful impact on local and global environmental degradation [6]. Moreover, various growing materials like sewage sludge, sawdust, spent mushroom compost; coco-nut coir dust and rice are also used locally in Pakistan as potting media in different combinations.

Among all the varieties of Antirrhinum majus L., dwarf variety is considered best for growing under container media. Therefore, keeping in view the composition, nutritional status and importance of growing media, the present study was intended to develop an efficient protocol for better growth of Antirrhinum cultivars in the most appropriate media to enhance their production for growers and the local markets.

\section{Materials and Methods}

The present research was carried out at Rose Project Area, Institute of Horticultural Sciences University of Agriculture Faisalabad during 2011-2012 to evaluate the comparative effect of different potting media on vegetative and reproductive growth of Antirrhinum majus L. 'Floral shower' the dwarf variety was evaluated. Seeds were purchased and nursery was established in propagation trays with growing media. Pots of 12 " were thoroughly filled with substrates according to treatments and three weeks old seedlings were transplanted. Substrate samples from each treatment were collected for morphological and chemical analysis. The experiment was carried out in Completely Randomized Design (CRD) and each treatment consisting of 10 plants was replicated thrice. The application of different treatments with composition given in table 1 .

Table 1. Composition of different treatments

\begin{tabular}{|c|c|}
\hline Treatments & Composition \\
\hline $\mathrm{T}_{0}$ & Control (silt+ topsoil)1:1 \\
\hline $\mathrm{T}_{1}$ & Leaf mould (Leaf mould + silt + topsoil) $1: 1: 1$ \\
\hline $\mathrm{T}_{2}$ & Farm yard manure (FYM + silt + topsoil) $1: 1: 1$ \\
\hline $\mathrm{T}_{3}$ & Peat moss (Peat moss + silt + topsoil) $1: 1: 1$ \\
\hline
\end{tabular}

\subsection{Plant Characteristics}

Data regarding all the growth indices was collected during research period. Plants were uprooted carefully and washed with tap water then with distilled water to record the following morphological attributes including: plant height $(\mathrm{cm})$, number of leaves and shoots plants ${ }^{-1}$, leaf area $\left(\mathrm{cm}^{2}\right)$, fresh and dry weight $(\mathrm{g})$, stem diameter $(\mathrm{cm})$, days to flower bud formation, days to flower bud opening, number of flowers per plant, flower bud diameter $(\mathrm{cm})$, flower diameter $(\mathrm{cm})$ and flower quality.

\subsection{Chemical Analysis}

Growth media was evaluated for the chemical properties such as $\mathrm{pH}$, electrical conductivity (EC), nitrogen (\%), phosphorus (ppm), organic matter (\%). A pH meter (digital ion analyzer) was used to measure the $\mathrm{pH}$ of the potting media and EC was measured in $\mathrm{dS} \mathrm{m}^{-1}$ with a conductivity meter. The total nitrogen in the soil sample was determined by distillation in Kjeldahl's apparatus and titration was carried out with standard $\mathrm{H}_{2} \mathrm{SO}_{4}$. Olsen's method was used to determine the available phosphorus in the media. For the estimation of organic matter (\%), $1 \mathrm{~g}$ air-dried sample was taken into a $500 \mathrm{ml}$ beaker, $10 \mathrm{ml} 1 \mathrm{~N}$ potassium dichromate solution and $20 \mathrm{ml}$ concentrated sulfuric acid using a dispenser were added and swirled the beaker to mix the suspension. After 30 minutes, $200 \mathrm{~mL}$ of distilled water was added along with $10 \mathrm{ml}$ concentrated orthophosphoric acid and mixture was allowed to cool. After adding diphenylamine as an indicator, beaker was placed the on a magnetic stirrer. Titration was done with $0.5 \mathrm{M}$ ferrous ammonium sulfate solution and reading was noted till color changed from violet blue to green.

\subsection{Statistical Analysis}

The collected data for the morphological traits of the plants and the chemical characteristics of the potting media were statistically analyzed by using analysis of variance (ANOVA) to check any differences between the means. The data was then subjected to Duncan's multiple range test (DMRT) for the comparison of means at a $5 \%$ probability level [12].

\section{Results}

\subsection{Effect of Different Potting Media on Growth Attributes of Antirrhinum majus}

Maximum increase $(13.5 \mathrm{~cm})$ in plant height was obtained in $\mathrm{T}_{1}$ followed by $\mathrm{T}_{3}(13.04 \mathrm{~cm})$ and $\mathrm{T}_{0}(11.10 \mathrm{~cm})$. The lowest plant height $(10.69 \mathrm{~cm})$ was observed in $\mathrm{T}_{2}$ (Fig. 1A). Data pertaining to number of leaves per plant exhibited highly significant results. Among the application of different treatments, plants produced more number (53.33) of leaves 
in $T_{3}$ which was statistically at par with $T_{1}$ (53.36). $T_{2}$ produced least number (38.63) of leaves in comparison to $\mathrm{T}_{0}$ (44.16) (Fig. 1B). Maximum number of shoots per plant was recorded in $\mathrm{T}_{1}$ (13.93) followed by $\mathrm{T}_{3}$ (13). A marked reduction (9.4) in number of shoots per plant was observed by $\mathrm{T} 2$ as compared to $\mathrm{T}_{0}(10.6)$ (Fig. 1C). The availability of nutrients in growing substrate greatly affects the size of leaves. Maximum increase in leaf area $\left(1.96 \mathrm{~cm}^{2}\right)$ was obtained when plants grown on $T_{1}$ followed by $T_{3}\left(1.69 \mathrm{~cm}^{2}\right)$ and $\mathrm{T}_{0}\left(1.56 \mathrm{~cm}^{2}\right)$. Reduction $\left(1.34 \mathrm{~cm}^{2}\right)$ in leaf area was observed in $\mathrm{T}_{2}$ grown plants (Fig 1D). Stem with thickest diameter have more mechanical strength to resist breaking and bending against stress environmental conditions. It is apparent from that statistical analysis that stem diameter had non-significant differences for all the potting media.
Maximum increase in stem diameter was showed by $\mathrm{T}_{1}(0.31$ $\mathrm{mm})$ while $T_{2}$ showed minimum $(0.28 \mathrm{~mm})$ stem diameter. Other treatments were recorded statistically non-significant (Fig. 1E). Plants attaining maximum increase in their fresh weights depict the nutrient rich growing media. Analysis of variance regarding fresh weight of plant showed highly significant results. Maximum increase in fresh weight of plant $(63.41 \mathrm{~g})$ was shown by $\mathrm{T}_{1}$ followed by $\mathrm{T}_{3}(58.44 \mathrm{~g})$ and $\mathrm{T}_{0}(46.45 \mathrm{~g})$. On the other hand, plants grown in $\mathrm{T}_{2}$ showed marked reduction $(22.02 \mathrm{~g})$ in fresh weight (Fig. 1F). A significant increase $(11.73 \mathrm{~g})$ in dry weight of plant was observed in $T_{1}$ which was statistically at par with $T_{3}(10.39$ g). A non-significant difference was recorded $\operatorname{inT}_{0}(5.50 \mathrm{~g})$ and $\mathrm{T}_{2}(4.58 \mathrm{~g})$ treatments (Fig. $\left.1 \mathrm{G}\right)$.
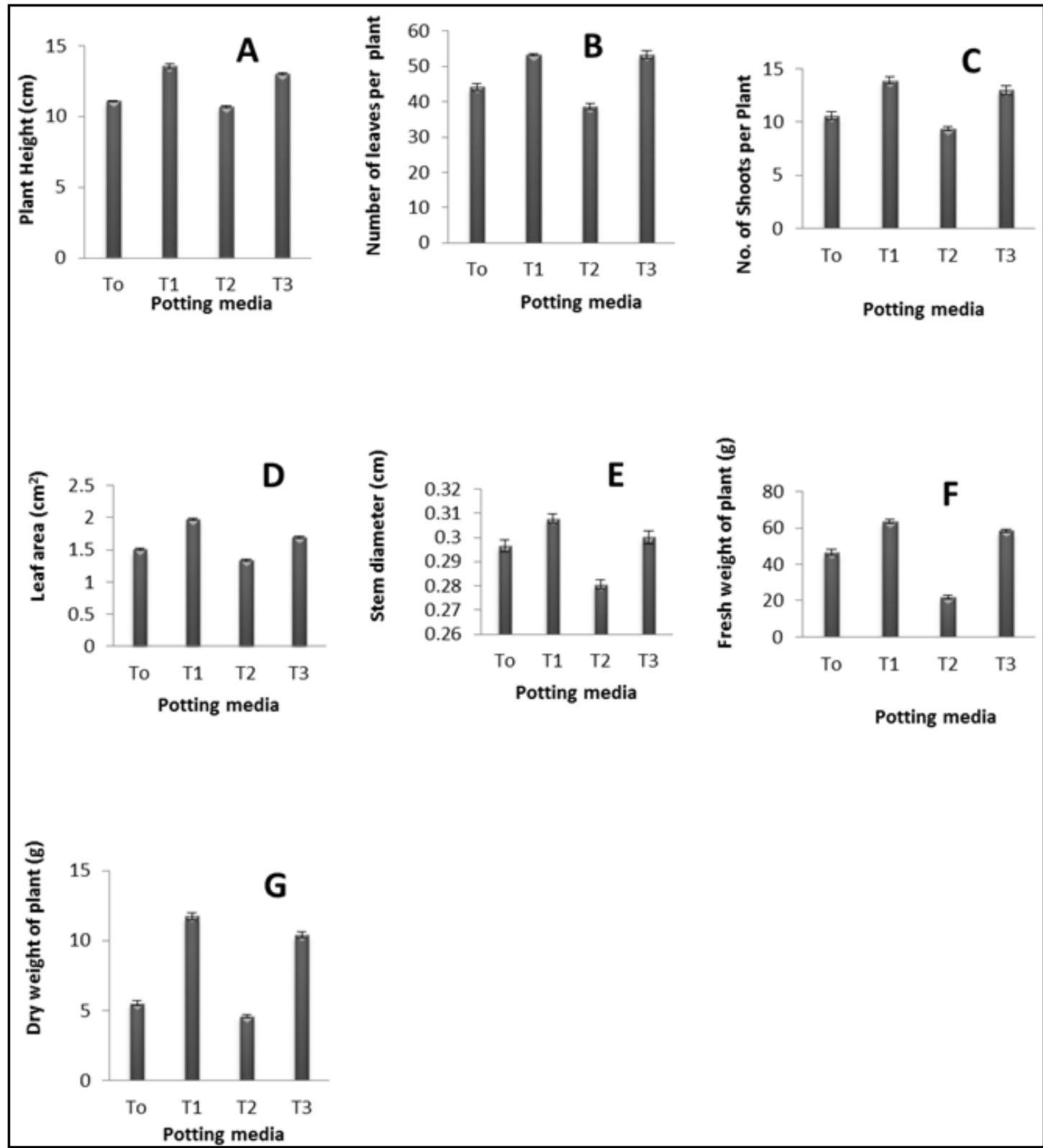

Figure 1. Effect of different potting media on growth attributes of Antirrhinum majus 


\subsection{Effect of Different Potting Media on Floral Attributes of Antirrhinum majus}

Potting media with rich nutrient contents showed to promote plant vegetative growth and delayed maturity and application of such growing substrates were seen to minimize the time taken by plant to give flower formation or emergence. $T_{2}$ took maximum days to flower bud formation (42.90) followed by $\mathrm{T}_{3}$ (39.43) which was statistically same with $\mathrm{T}_{0}(40.10)$. $\mathrm{T}_{1}$ took minimum days (37.70) to flower bud formation (Fig. 2A). Among the application of different treatments, $\mathrm{T}_{2}$ took maximum days (56.03) to flower bud opening. Other treatments showed no significant difference among each other and were statistically alike with $50.90,49.30$ and 50.10 for $T_{0} T_{1}$ and $T_{3}$ respectively (Fig. 2B). Maximum flowers production in plants highlights their adaptability to suitable environment. Data regarding the number of flowers per plant was subjected to analysis of variance showed highly significant results. Among the application of different treatments, $T_{1}$ produced maximum number (22.83) of flowers per plant followed by $\mathrm{T}_{3}(22.73)$ and $\mathrm{T}_{0}$ (19.76). $\mathrm{T}_{2}$ produced less number of flowers (7.83) per plant (Fig. 2C). Data regarding flower bud diameter showed significant results for flower bud diameter. Maximum flower bud diameter was found in $\mathrm{T}_{1}(0.71 \mathrm{~cm})$ followed by $\mathrm{T}_{3}(0.66 \mathrm{~cm})$. A gradual reduction in flower bud diameter in $\mathrm{T}_{0}(0.62 \mathrm{~cm})$ and $\mathrm{T}_{2}(0.55 \mathrm{~cm})$ was observed (Fig. 2D). Maximum increase in flower diameter was observed in $\mathrm{T}_{1}(0.98 \mathrm{~cm})$ followed by $\mathrm{T}_{3}$ $(0.89 \mathrm{~cm}) . \mathrm{T}_{2}$ showed less increase $(0.68 \mathrm{~cm})$ in flower diameter. (Fig. 2E). Rich supply of nutrients like $\mathrm{K}, \mathrm{N}$ and $\mathrm{P}$ in growing substrate is sufficient for production of good quality flowers. $T_{1}$ produced best quality flowers (7.73) followed by $\mathrm{T}_{3}$ (7.40) and $\mathrm{T}_{0}(7.03)$ whereas, $\mathrm{T}_{2}$ exhibit poor quality flowers (5.26) than all the treatments (Fig. 2F).

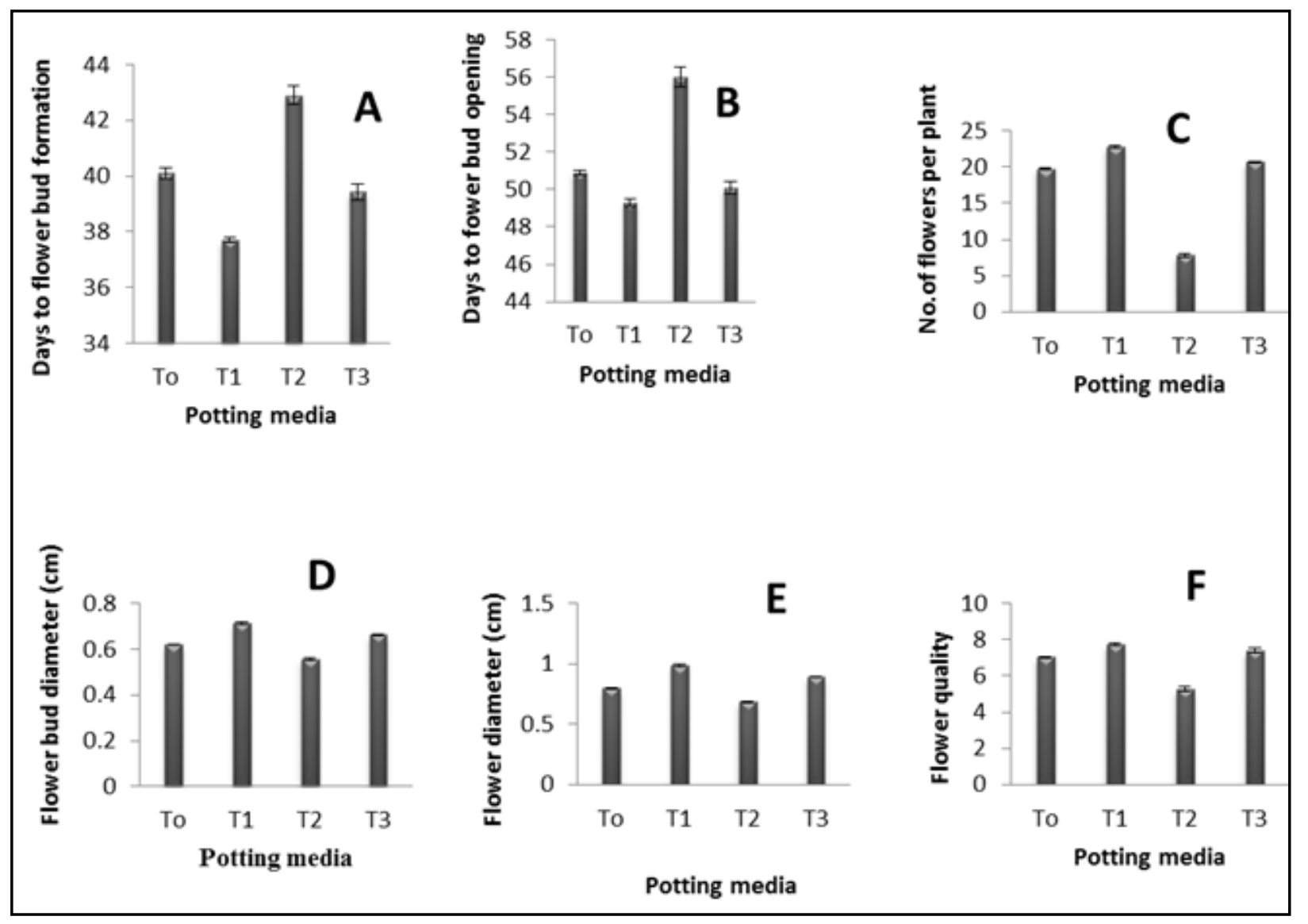

Figure 2. Effect of different potting media on floral attributes of Antirrhinum majus

\subsection{Effect of Different Potting Media on Chemical Attributes of Antirrhinum majus}

Accessibility of nutrients to plants in growing media is coupled with the changes in media $\mathrm{pH}$. It is evident from statistically analyzed data that there was no significant difference in $\mathrm{pH}$ of different potting media. Maximum media $\mathrm{pH}$ (7.7) was observed in plants grown in $T_{0}$ and minimum (7.5) in $T_{2}$ media. Other treatments $T_{1}$ and $T_{3}$ (7.6) were statistically alike among each other (Fig. 3A). It is depicted that application of different potting media had a significant effect on the electrical conductivity. Maximum value (9.5) of $\mathrm{EC}$ was recorded in $\mathrm{T}_{2}$ followed by $\mathrm{T}_{3}(5.5)$ which were statistically at par (5.4) with $\mathrm{T}_{1}$ Minimum value (4.5) of EC was observed in $\mathrm{T}_{0}$ (Fig 3B). Total $\mathrm{N}$ content was obtained in potting media $\mathrm{T}_{2}$ that showed the best results for $\mathrm{N}$ content $(0.083 \%)$ which was statistically similar to $\mathrm{T}_{0}(0.082)$. Least $(0.063 \%)$ and medium $(0.073 \%)$ 
amount of $\mathrm{N}$ content was observed in $\mathrm{T}_{1}$ and $\mathrm{T}_{3}$ respectively (Fig. 3C). Maximum phosphorus contents were present in $\mathrm{T}_{2}$ (20.50) followed by $\mathrm{T}_{1}$ (20.30) which was statistically at par with $\mathrm{T}_{3}(20.10 \mathrm{ppm})$, whereas, minimum contents $(14.5 \mathrm{ppm})$ were observed in $\mathrm{T}_{0}$ (Fig 3D). Among the application of different potting media, maximum value for organic matter was found in $\mathrm{T}_{2}(1.25)$, whereas, a non-significant difference was observed among all other treatments $\mathrm{T}_{0}, \mathrm{~T}_{1}$ and $\mathrm{T}_{3}(1.14 \%, 1.15 \%$ and $1.16 \%$ ) respectively (Fig. 3E).

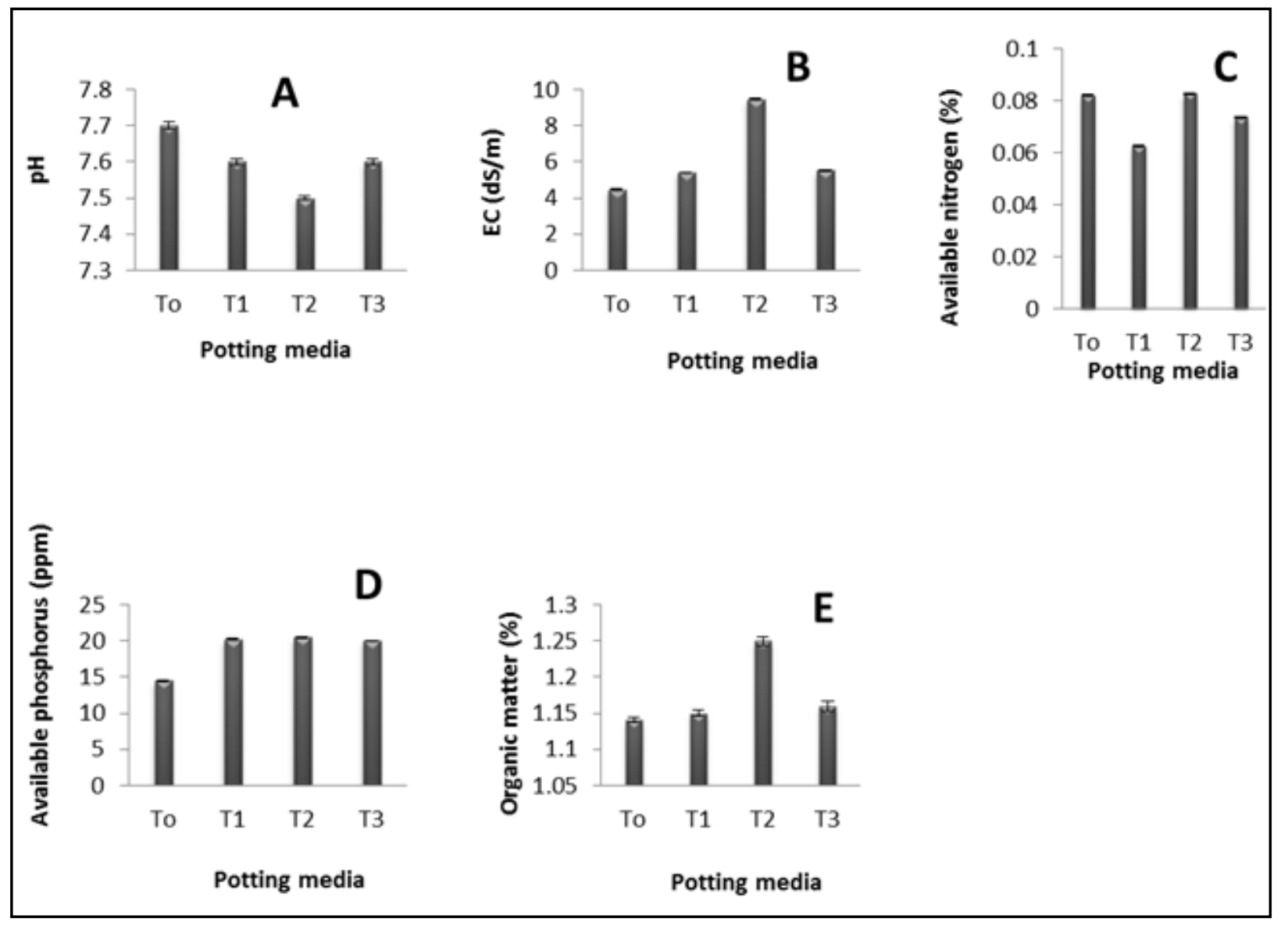

Figure 3. Effect of different potting media on chemical attributes of Antirrhinum majus

\section{Discussion}

A balanced rooting medium that contains an adequate supply of nutrients is essential for plants to attain maximum growth and development. Balanced rooting media greatly affects the plant height and availability of growing substrate with the supplement of essential nutrients is essential for attaining maximum plant height Ikram [13] Results showed that use of different potting media affect plant height differently. Maximum increase in plant height was attained in Leaf Mould media which might be due to maximum uptake of nutrients [14]. Our findings are in line with Bashir [15] who observed maximum plant height in Dieffen bachia plants in Leaf Mould potting media. Maximum plant growth in Geraniums was also obtained when Leaf Mould and Peat growing substrates were used [16]. Similar findings were reported by Dubsky [17] who reported excellent growth of perennials in Leaf Mould and peat substrate with the addition of rock wool and observed maximum plant height under such media. Increase in plant height under Leaf Mould potting media was also supported by Treder [18].
Major food manufacturing units in plants are leaves that are influenced by environmental conditions and soil is one of the factors which have prime importance in this regard. More number of leaves in plants reflects its good vigor and suitability of environment. It is depicted from results that maximum number of leaves in plants obtained in potting media containing Leaf Mould which is in accordance with the findings of Khayyat [19] who found leaf mould is the best growing substrate in combination with cocopeat $(3: 1)$ for attaining more number of leaves. Riaz [20] found significant results for leaf numbers in a growing media with the combination of silt + leaf Manure + coco coir substrates. According to Benito [21] peat and leaf manure as growing substrates with adequate supply of nitrogen content are good for healthy plant growth.

Maximum increase in number of shoots per plant highlighted the vigorous vegetative plant growth. Nutrient rich growing media promotes the growth of plants. Results depicted that treatments having Leaf Mould and peat moss in combination with silt + topsoil produced maximum number of shoots per plant which showed the enhanced vegetative 
growth in Antirrhinum majus L. These findings are confirmatory with Bashir [15] who noted the maximum number of shoots of Sinmondsia chinensis in Leaf Mould. Similar finding were also reported by Riaz [20] in ornamental plants having much increased side branches in coconut compost growing media in combination with silt + leaf manure.

The availability of nutrients in growing substrate greatly affects the size of leaves. Best substrate having adequate supply of nutrients can be used to accomplish significant results. Maximum increase in size of leaves shows adaptability of plants to soil. Best results regarding leaf area were obtained in media comprising Leaf Mould and peat moss when used alone in combination with silt + topsoil. These results are in line with Khayyat [19] who found maximum increase in leaf area of Epipremnum aureum Lindl. Moreover, results highlighting maximum increase in leaf area are also in agreement with Turhan [14] who found significant results for carnation in growing substrate containing rice husk mixed with Leaf Manure.

Stem with thickest diameter have more mechanical strength to resist breaking and bending against stress environmental conditions. Plants exhibiting maximum stem diameter with strong vigor can be used successfully. Leaf Mould medium showed maximum stem diameter was in agreement with Kiran [22] who observed thickest stem of Dahlia in sand + silt + Leaf Mould medium.

Ornamental plants grown under different potting media showed their suitability to the media. Plants attaining maximum increase in their fresh weights depict the nutrient rich growing media. Results showed that plants gave maximum increase in fresh weight in Leaf Mould and peat moss containing media. In this regard, Wang and Konow [2] observed highest increase in fresh weight of plants in peat comprising medium than any other media. Such findings are also in accordance with Treder [18] who observed flowers maximum fresh and dry weights in the same substrates. Liopa [23] documented Leaf Mould as the growing substrate increasing fresh and dry weights of tarragon and lemon balm plants. Highest increase in dry weight was obtained when Leaf Mould and peat moss were used as a potting medium in combination with silt + topsoil. Similar results were observed for Epipremum aureum by Khayyat [19]. Moreover, results depicted by Chavez [24] also found marked increase in Petunia hybrida plant when grown in Leaf Mould and river waste.

Potting media with rich nutrient contents showed to promote plant vegetative growth and delayed maturity and application of such growing substrates were seen to minimize the time taken by plant to give flower formation or emergence. Results showed that use of Leaf Mould potting media took minimum days to flower bud formation among all other treatments. These results were in accordance with Kiran [22] who also examined minimum days for flower bud formation of Dahlia (Dahlia pinnata L.) for same substrate. It was observed that application of Leaf Mould took minimum days to flower bud opening among all other treatments. Grassotti [25] also found minimum days for lily and gladiolus flower emergence. Flowering plants seem more attractive and marvelous and frequently used in landscape. Maximum flowers production in plants highlights their adaptability to suitable environment. It was observed that adequate availability of nutrients such as $\mathrm{K}$ and $\mathrm{P}$ in growing media provide significant results regarding growth and flowering indices. Nowak and Strojny [26] observed that optimum amount of $\mathrm{P}$ in organic residues provide maximum increase in flowering. Best results regarding more number of flowers per plant which were achieved in silt + topsoil + Leaf Mould media are similar to the results of Kiran [22] who observed more number of flowers for Dahlia (Dahlia pinnata) in same combination.

Accessibility of nutrients to plants in growing media is coupled with the changes in media $\mathrm{pH}$. Increase or decrease in $\mathrm{pH}$ has direct effect on plant growth and development. Changes in $\mathrm{pH}$ above or low than the optimum range adversely affects plants by damaging roots and decreasing nutrient availability. Awang [27] reported the best $\mathrm{pH}$ range (5.9-7.0) for plants better growth and development. Our findings showed that $\mathrm{pH}$ was ranged between 7.5-7.7 in all the treatments. Increase in $\mathrm{pH}$ induced reduction in $\mathrm{N}$ and $\mathrm{P}$ contents of potting media [28]. Electrical conductivity (EC) provides a measurement of dissolved salts in soil which affects the plant growth [29]. The best range of dissolved salt contents in soil reveals the better plant growth [25]. Maximum EC (9.5 $\left.\mathrm{dS} \mathrm{m}^{-1}\right)$ was found in FYM treatment. Due to high EC value, FYM showed minimum results regarding growth parameters than all other treatments. Results are coordinated with Miller [30] who found that substrate having higher EC affects the plant growth.

Organic matter in growing substrate and optimum amount of $\mathrm{N}, \mathrm{P}$ and $\mathrm{K}$ manipulate plant growth and flower size. Media comprising peat encloses mainly phosphorus. Different potting media were used with different proportions and best results for flower diameter were obtained when Leaf Mould and peat moss were used in combination with silt + topsoil. Such findings were in agreement with Riaz [20] who found that growing substrate with adequate availability of nitrogen and potassium with high increase in flower diameter. Rich supply of nutrients like K, N and P in growing substrate is sufficient for production of good quality flowers. Good quality flowers were obtained in leaf mould and peat moss containing media. These results are supported by Younis [31] who reported similar findings for Chrysanthemum under with combination of different substrates.

It was observed that all of the growing substrates exhibit nutrient supply however, the availability of nitrogen content up to the maximum was found in FYM but due to higher $\mathrm{pH}$ and EC value of growing substrate, it restricted the $\mathrm{N}$ availability to plants ultimately plant growth depressed. Such findings are supported by Altland [28] who found that reduction in available $\mathrm{N}$ content due to high $\mathrm{pH}$ decreased the growth of hydrangea (Hydrsngea macrophylla Thunb), japanese maple (Acer paloiatiioi var. atropurpureum Thunb.) and leueothoe (Leueothoe axillaris Lam.). Peat showed best 
results regarding several growth indices due to optimum nutrients availability. Growing substrate with excellent nutrient quality influences plant growth. Availability of $\mathrm{P}$ contents in soil has positive relationship with flowering indices. Treder [18] reported that plants have long stem and maximum number of flowers in growing media with optimum phosphorus contents. Potting media comprising FYM showed maximum amount of P content. Younis [31] results who observed maximum flowering of Dahlia coccinia in high P content substrate. Organic matter in potting media promotes the plant growth due to high availability of nutrients [32]. Maximum organic matter was found in FYM containing substrate while other treatments showed no significant results and it might be due to substrate natural fertility. Chemical attributes of high organic matter encourage the plant growth and peat also improves good substrate in this regard [33].

It is concluded from the comparative study that agricultural and municipal wastes are good, cheap potting media components for the production of flowering plants. An economical and high-quality production of 'Floral shower' can be attained by using most suitable media. Application of Leaf Mould in combination with silt + topsoil showed best results regarding plant growth. Peat moss containing growing substrate also showed positive results for plants vegetative and reproductive growth. However, Farm Yard Manure was seen to prove less effective for better plant growth due to its less contribution for the availability of nutrients. Availability of $\mathrm{P}$ contents in soil has positive relationship with growth and flowering indices. Maximum amount of available P content was found when Farm Yard Manure and Leaf Mould were used alone in combination with silt + topsoil. Thus, it is suggested that Leaf Mould can be recommended as a standard potting media for Antirrhinum majus L. growth.

\section{REFERENCES}

[1] D.C. Albach, H.M. Meudt, B. Oxelman. Piecing together the "new" Plantaginaceae. American Journal of Botany, No. 92, $297-315,2005$

[2] T. Wang, E. A. Konow. Fertilizer source and medium composition growth of Moth Orchid, Horticultural Sciences, Vol.34, 515-520, 1999.

[3] M. N. Rogers. Snapdragons. In: Introduction to Floriculture. 2nd Ed., R. A. Larson. Academic Press, New York, 93-112, 1992.

[4] U. Tariq, S. Rehman, M. K. Aslam, A. Younis, M. Yaseen, M. Ahsan. Agricultural and municipal waste as potting media components for the growth and flowering of Dahlia hortensis 'Figaro', Turkish Journal of Botany, Vol.36, 378-38, 2012.

[5] S. B. Wilson, P. J. Stoffella, D. A. Graetz. Development of compost based media for containerized perennials, Science of Horticulture, Vol.93, 311-320, 2002.
[6] H. M. Ribeiro, A. M .Romero, H. Pereira, P. Borges, F. Cabral, E. Vaconcelos. Evaluation of a compost obtained from forestry wastes and solid phase of pig slurry as a substrate for seedlings production. Bioresource Technology, Vol.98, 3294-3297, 2007.

[7] M. Grigatti. Growth and nutritional status of bedding plants on compost-based growing media. Acta Horticulturae, Vol.779, 607-614, 2008.

[8] Y. Kashihara, K. Shinoda, N. Murata, H. Araki, Y. Hoshino. Evaluation of the horticultural traits of genus Alstroemeria and genus Bomarea (Alstroemeriaceae). Turkish Journal of Botany, Vol.3, 239-245, 2011.

[9] Z. Khan, S. A. Tiyagi, I. Mahmood, R. Rizvi. Effects of N fertilization, organic matter and biofertilizers on the growth and yield of chili in relation to management of plant-parasitic nematodes, Turkish Journal Botany, Vol.36, 73-81, 2012.

[10] Bulluck, and J. B. Ristaino. Effect of synthetic and organic soil fertility amendments on southern blight, soil microbial communities, and yield of processing tomatoes. Phytopathology, Vol.92, No.2, 181-189, 2002.

[11] G. E. Fitzpatrick. Sludge processing effects on compost quality. BioCycle, Vol.27, 32- 35, 1986.

[12] R. Steel, J. H. Tome, D. Dickey. Principles and Procedures of Statistics, A biometrical approach, 3rd ed., McGraw-28 Hill Publications, New York, 1997.

[13] S. Ikram, U. Habib, N. Khalid. Effect of different potting media combinations on growth and vase life of Tuberose (Polianthes Tuberosa Linn.), Pakistan Journal of Agricultural Sciences, Vol.49, No.2, 121-125, 2012

[14] H. Turhan, F. Kahriman, C. O. Egesel, M. K. Gul. The effects of different growing media on flowering and corm formation of saffron (Crocus sativus L.). African Journal of Biotechecnology, Vol.6, 2328-2332, 2007.

[15] M. A. Bashir, M. Ahmad, M. A. Anjum, 2007. Effect of various potting media on growth of rooted jojoba (Simmondsia chinensis) cuttings. International Journal of Agriculture and Biology, Vol.9, 147-151, 2007.

[16] J. C. Ostos, R. Lopez-Garrido, J. M. Murillo, R. Lopez. Substitution of peat for municipal solid waste and sewage sludge-based composts in nursery growing media: Effects on growth and nutrition of the native shrub Pistacia lentiscus L, Bioresource Technology, Vol.99, 1793-1800, 2008.

[17] M. Dubsky, F. Sramek. Crushed rockwool as a component of growing substrates, Acta Horitculturae, Vol.779, 491-495, 2008.

[18] J. Treder. The effects of cocopeat and fertilization on the growth and flowering of oriental lily 'star gazer', Journal of Fruit Ornament and Plant Research, Vol.16, 361-370, 2008.

[19] M. Khayyat, F. Nazari, H. Salehi. Effects of different pot mixtures on pothos (Epipremnum aureum Lindl. and Andre 'Golden Pothos') growth and development. Am-Euras. Journal of Agriculture and Environmental. Sciences, Vol.2, 341-348, 2007.

[20] A. Riaz, M. Arshad, A. Younis, A. Raza, M. Hameed, Effect of different growing media on the growth and flowering of Zinnia elegans cv. Blue Point. Pakistan Journal of Botany, 
Vol.40, 1579-1585, 2008.

[21] M. Benito, A. Masaguer, R. D. Antonio, A. Moliner. Use of pruning waste compost as a component in soil less growing media, Bioresource Technology, Vol.96. 597-603, 2005.

[22] M. Kiran, J. Din, K. Waseem, M. S. Jilani, M. Q. Khan. Effect of different growing media on the growth and development of Dahlia (Dahlia pinnata) under the agro-climatic condition of Dera Ismail Khan, Pakistan Journal of Biological Sciences, Vol.10, 4140-4143, 2007.

[23] A. Liopa-Tsakalidi, D. Chalikiopoulos, A. Papasavvas. Effect of chitin on growth and chlorophyll content of two medicinal plants, Journal of Medical Plants Research, Vol.4, 499-508, 2010.

[24] W. Chavez, A. D. Benedetto, G. Civeira, R. Lavado. Alternative soilless media for growing Petunia hybrida and Impatiens wallerana: Physical behavior, effect of fertilization and nitrate losses. Bioresource Technology, Vol.99, 8082-8087, 2008.

[25] A. Grassotti, B. Nesi, M. Maletta, G. Magnani. Effects of growing media and planting time on lily hybrids in soilless culture, Acta Horticultrae, Vol.609, 395-399, 2003.

[26] J. S. Nowak, Z. Stronjy. Changes in physical properties of peat based substrates during cultivation period of gerbra, Acta Horticulturae, Vol.644, 319-321, 2004.
[27] Y. Awang, A. S. Shaharom, R. B. Mohamad, A. Selamat. Growth dynamics of Celosia cristata grown in cocopeat, burnt rice hull and kenaf core fiber mixtures. American Journal of Agrculture and Biological Sciences, Vol.5, 70-76, 2010.

[28] J. E. Altland. Substrate pH, a tricky topic, Digger, Vol.50, 42-47, 2006.

[29] N. Brady, R. Weil. The nature and properties of soils, 12th ed. Prentice, New Jersy, 1996.

[30] M. Miller. Fulfilling special needs of nurseries, Biocycle, Vol.42, 65-67, 2001.

[31] A. Younis, A. Riaz, M. Waseem, M. A. Khan, M. Nadeem. Production of quality croton (Codiaeum variegatum) plants by using different growing media. Journal of Agriculture and Environmental Science., Vol.7, 232-237, 2010.

[32] L. H. Fraser, S. M. Carty, D. Steer. 2004. A test of four plant species to reduce total nitrogen and total phosphorus from soil leachate in subsurface wetland microcosms. Bioresource Technology, Vol.94, 185-192, 2004.

[33] M. Abad, P. Noguera, S. Bures. National inventory of organic wastes for use as growing media for ornamental potted plant production: case study in Spain, Bioresource Technology, Vol.77, 197-200, 2001 